\title{
Feminist Attributes for Parenting: Suggested by Adichie
}

\author{
Kanika Chauhan \\ Guest Faculty \\ Maitraiye College NCWEB \\ Delhi University \\ Delhi, India \\ kanikarajora@gmail.com
}

Abstract

Chimamanda Ngozi Adichie, is a contemporary Nigerian writer. I choose her work

Dear Ijeawele, Or, A Feminist Manifesto In Fifteen Suggestions, as it gives suggestion for parenting in a feminist manner. A series of personal letter accommodated in a book are refreshing take on parenting and can be studied as an initial guide to understand feminism as an ideology. My main focus with this paper is to focus on two different kinds of parenting suggested by her and by Lois Gould, from her short story The story of X, where she creates a narrative revolving around gender-neutral parenting, and how these two can be read together to give a refreshing take on parenting, which is radical in nature because it dissects the norms.

Keywords: Nigerian Literature, Feminism, womanhood, parenting, gender-neutral Literary traditions in Nigeria, as throughout Africa are highly based on the opposition of colonialism and Euro-American Literature. The theories of the development of the Africa literature is divided into the age of Anti-colonial struggle, the age of independence and the age of neo-colonialism. The writers like Chinua Achebe wrote before or after the independence and writings were based on the themes of struggle and oppression of colonisation. These ages have been divided by many Nigerian critics in three generations. 
The new generation of writers have designated with the third generation in Nigeria; those who have published their works in and after 1980s. The exclusion of women writers mainly from the first two generations of the Nigerian Literature is noticeable. Nigerian Literary Canon has been criticized by the women writers. Women writers like Toyin Adewale who voiced out many questions in the introduction to Breaking the Silence, a collection of short fiction, where she raised the question about: where are the women and sisters in our literature? Women were excluded from the canon. They faced gender specific obstacles, which are highly based on economic, cultural and psychological—which creates more obstacles to write and or the combination that make them silent. One of the obstacles faced by them is because their writings are different from previous generations. The stagnant nature of Nigerian Literature that doesn't want to include newer work and different variants of writing, which gives contemporary picture of Nigeria. My point of highlighting these problems were to bring up the emerging writer in Nigerian Literature and a feminist Chimamanda Ngozi Adichie.

Being now one of the prominent faces of Nigerian Writers, her works need attention for several reasons. Her works expands understanding of thirds generation Nigerian writers, her fictions focuses various influences on Nigerian writers particularly from first generation. The intertextuality suggested in her works, presence the diverse nature within contemporary Nigeria Literature. A close examination of her works suggests the inclusion of writing in the literary canon. My attempt with this paper is to suggest some works by Adichie and as being a feminist her approach to writing is very global and direct to put forth the stand of women in society in twenty first century. Her works suggest a better understanding of feminism and identification of women in the society. Her most noticeable works like Purple Hibiscus (2003), Americanah (2013) talks about the Nigeria and the perspective of women in her writings needs to be studied separately. 
"But by far the worst thing we do to males - by making them feel they have to be hard - is that we leave them with very fragile egos. The harder a man feels compelled to be, the weaker his ego is. And then we do a much greater disservice to girls, because we raise them to cater to the fragile egos of males."

I like to elucidate this further about Adichie by her much talked about TEDx talk in 2012 "We all should be feminists" which later got published as an essay. She talks about the feminism in the context of twenty first century. By giving many anecdotes from her person life, she points out many wrongs in the very progressive society. Her experience as African feminist and her views on gender construction and the faults in such construction. Very vital points she makes is which many young females can relate to is: Feminism comes with baggage, a negative baggage, that's how society associates it with. She elucidates it further on how she always keeps on adding words before 'Feminist' to remove that negative connotation: from Feminist to Happy Feminist—because Feminists are angry, and this goes on. In addition to this, my understanding from her essay is the fact that majority of population thinks that we are 'progressive' and that 'we have enough knowledge for both genders to make right decisions'. Of course, we are progressive but question still remains unanswered about how progressive we are when it comes to gender roles both in public and private settings. How we treat our women and how we are upbringing both the sexes in our Progressive society. She further points out:

"If we do something over and over, it becomes normal. If we see the same thing over and over, it becomes normal.... If we keep seeing only men as heads of corporations, it starts to seem "natural" that only men should be heads of corporations."

This normalisation with locating women with domestic life is where one should question their evolvement in the society as progressive human. Seeing women on top is 
something taken as surprise, why? Because she is a woman she doesn't belong there. There is a time when one need to specifically change the norms and labelled associations with genders. We associate girls with what men think of them and their primary goal is getting married. But same is not the case with boys.

My main motive to write about Adichie to bring forth her work called Dear Ijeawele or a Feminist Manifesto in Fifteen Suggestions (2017). It's a collection of person letters she wrote to her friend, who gave birth to a girl and wanted to ask how to raise her to be a feminist. It is something anyone who is not aware or aware about feminism can read and get a better understanding, a better picture of feminism in very simple manner. Because even when we think we are on a progressive road towards Equality we tend to miss very small attributes because patriarchy is embedded in us so deeply.

Before going straight to the attributes of this work, I want to put some emphasis on Gender Neutral Parenting. Lois Gould wrote a short story 'The Story of X', a brilliant short work where she talks about gender neutral parenting. The story shows the idealistic parenting. The story of Secret Scientific Xperiment knows as the project baby X. Where Baby $\mathrm{X}$ will remain neutral and no one will know whether the Baby $\mathrm{X}$ is boy or girl. The baby $\mathrm{X}$ will not stay $\mathrm{X}$ forever, gradually Baby $\mathrm{X}$ will decide what kind of things it will like and move away from the binary of girl and boy which usually how we raise our child to be. Gender Neutral Parenting can solve these problems. At the time of basic age, they will overcome the problems of this stratum, which will help in the better upbringing of society. The story shows two alternative systems to deal with the situation. One side the parents of X, who are willing to bring this change and break this binary. The others are the parents of students who study with $\mathrm{X}$ and how they have problem with it, and who are not ready to give up the binary of Boy and Girl. The story also shows the difficulties of such parenting by giving many examples of using Manual Guide to tackle with such problems. At the basic age, 
upbringing of this kind will clarify many confusions which kids usually face at the time of adolescence, sex education will not be surprising factor for them but something which they are learning gradually from the basic age. The gender-neutral parenting can only happen when we are exposed to everything. Being aware of plurality is very important which we never actually focus on. It can help build the better relationship with parents also. The story of $\mathrm{X}$ is not utopian, it is possible with thousands of challenges of course. Unlearning is very important and yet the most difficult challenge because breaking from the rigidness of stereotypes is not an easy task.

My reason for bringing this up is to give the background of such parenting and my understanding of it, and how we can accommodate a very contemporary work by Adichie to help raise the children in better environment away from the stereotypes. Dear Ijeawele or a Feminist Manifesto in Fifteen Suggestions focuses on this in a very simple manner to raise girls to be a feminist. My reading of this text suggests that it's not for only girls but for both genders. Here she was addressing it to her friend who wants to raise her daughter to be a feminist but the approach can be taken for everyone. Why both these texts can be accommodated together is because they both talk about a different kind of parenting. Which is very important today to understand because where we are heading in this progressive word lacks plurality of society which needs to be recognized.

Dear Ijeawele or Feminist Manifesto in Fifteen Suggestions, as I said before talks about feminism in a very simple manner and makes it easy for any individual to get a better hold of it, if they are willing to. In the beginning, she talks about two tools of being feminist, Premise and Questioning. Premise, is something which we need to understand and stick with it. Something you cannot compromise with. That I matter, equally and not with 'if only'. The ability to question, things which happens around us, out of curiosity, out of lack of equality, always question. Throughout this discourse of feminism, questioning can be seen as a major 
tool because it is important in any kind of revolutionary. Primarily it is to understand and question.

In the first two suggestions she talk about parenting and motherhood. Motherhood is beautiful but don't define yourself with it. Be a full person. It is important to understand that women associate themselves with being a mother and not an individual person. They associate themselves in the domain of domestic life and girls are brought up like that only. Parenting is something which is decided mutually, so the time put forth in it should be mutually divided also. Women should not leave their jobs because they need to take care of her their new born. Working women should be given equal respect as the working men. Women should not compromise to her own self because she is a mother now. Because when we reverse the role a man is also becoming a Father, a total new identity. Domestic work should be gender neutral. Doing together should be the motive rather than doing it all. Woman need to understand that bringing a child up is as much father's domain as it is of mothers. And man is not helping you but he is just being a father. The one of the major aspect of gender neutral parenting is to understand the roles you perform in day to day life. Elaine Showalter talks about this by referring to Nancy Chodorows's concept of shared parenting. Showalter's understanding is that

"shared parenting, the involvement of men as primary caretaker of children, will have a profound effect on our sense of sex difference, gender identity and sexual preference."

It is important to understand that gender neutral parenting as suggested in 'The story of $\mathrm{X}^{\prime}$ is not a one-way road but two ways, where as much as upbringing of a child should be neutral. There is so much to unlearn for parents also and goes towards a shared parenting. Because as parenting is a verb which is for both father and mother, we need to recognize this 
fact and only then we can go further to raise children differently from the stereotypical parenting.

In the third suggestion, she elucidate the problem with Gender Roles:

"Gender roles are so deeply conditioned in us that we will often follow them even when they chafe against our true desires, our needs, our happiness. They are very difficult to unlearn, and so it is important to try to make sure that Chizalum rejects them from the beginning. Instead of letting her internalize the idea of gender roles, teach her self-reliance. Tell her that it is important to be able to do for herself and fend for herself. Teach her to try to fix physical things when they break. We are quick to assume girls can't do many things. Let her try. She might not fully succeed but let her try. Buy her toys like blocks and trains - and dolls, too, if you want to." Adichie here I think absolute do justice to the parenting about how gender-neutral parenting should be. The basic binary created between two genders are specified by their gender roles in society. And it is so deeply embedded in us that even when we try, we give away with it. Before even a kid is born, we put it in this binary. And we raise them in that manner. In Adichie's suggestion of not restricting her in these roles is one of the toughest tasks as parents to do so. Not only for the little girl but for parents and the first step should be taken by parents or any individual to understand it about how they are going to unlearn the gender roles. Putting women in the frame of domestic life is due to assigned gender roles and we need to break that binary. Domestic work should be learned by everyone and one should not be dependent on anyone for it. It's a work in general, a life skill to survive which we learn, and we restrict it to only one gender. Moreover, we judge women in the perspective of marriage on the basis of how good cook she is, by doing that we create this hierarchy where not only does she needs to know how to cook but how she is subordinate to her husband. Because if we reverse the roles, men don't have to go through this test of being a perfect 
groom. It puts domestic work in the lesser position also but it is a life skill of surviving which every individual should learn.

Her suggestion about convenient feminism needs to be highlighted. The term Feminism Lite which she talks about is the ideal condition of feminist equality, which is hollow. Feminist is an ideology which you either accept or not accept. There is no middle ground but in recent years this middle ground is created which is faulty, to convey the message of feminism, which many revolutionaries worked hard for is in a wrong light because of this. One cannot be conveniently feminist. She says:

"Feminism Lite uses analogies like 'he is the head and you are the neck'. Or 'he is driving but you are in the front seat'. More troubling is the idea, in Feminism Lite, that men are naturally superior but should be expected to 'treat women well'. No. No. No. There must be more than male benevolence as the basis for a woman's well-being."

The "Allowing" nature of the feminism lite is where the fault lies. When we talk about equality, this is not the message we convey and one need to stay away from it. Allow is about power, which is subscribed to men over women. If you are Allowing her to go and do certain things, it is as faulty as restricting her. Women become so conditioned with these situations that they can't associate themselves out of it. For them freedom is actually not freedom but freedom with certain limitations, certain boundaries which they can cross. Freedom come as favour to them. The saddest part of feminism lite is young generation is bending towards this false notion of feminism because it is more convenient to them. Adichie suggests that one need to make sure to not fall in this trap.

She suggests to raise kids to question language and read. Because language bring our cultural norms, our beliefs and prejudices. When we ask questions about language, it automatically reflects on the history of a kind. So, when a child will be able to question it, she 
will able to understand and decide it. Her suggestion to not name tag kids (like princess or superhero) because even that creates this binary of gender roles. Use of words misogyny and patriarchy in everyday basis by giving examples to make them understand the history behind them and how they embedded in our society. Most importantly because of this make them question the layers of society, small things which we tend to avoid. Once they will start understanding these binaries, they will question them. Putting women in a position where they resist themselves in every possible situation does not come out of nowhere but the upbringing matters. We don't do that with boys. This is something she needs to question. "Teach her that if you criticize $\mathrm{X}$ in women but do not criticize $\mathrm{X}$ in men, then you do not have a problem with X, you have a problem with women. For X please insert words like anger, ambition, loudness, stubbornness, coldness, ruthlessness."

This hierarchy is not constructed in our minds by birth, but they are created slowly by normalising them. Her stubbornness, her questioning should not be criticized on the ground of being a girl and that 'she is out of character of girl', but on the basis of merits not on the basis of sexism.

Next, she suggests about the institution of marriage. Marriage is not an achievement or something young girls aspire to do. They should aspire to get education and get job and be economically stable but not marriage. From the beginning we give too much importance to marriage. We make sure that girls evolve their world around it. But not the same case with boys. There is certain limitation to girls even when they are educated, particular age of marriage which is embedded in them from the very beginning and only till then they have time to make career. Marriage is an institution which should come at the time when it is right for any individual. But certainly, the case is different. Everything for woman changes after marriage, from sir name to the title of Mrs. Why this is not for men and why no one questions it. Because we make sure that by talking about it again and again and normalising it will 
make it hard to become a question. And we need to get away with it. We need to teach girls and boys to aspire for knowledge and to make sure they question. And not about marriage as an institution.

We teach our girls to be likeable and be nice. Adichie suggestion to this is that this is false. By being too occupied in order to be likeable will not let your put forth your opinions. To elucidate her point, I want to point out that while upbringing girls especially we make sure to create an environment of domesticity around them. We make them sit in certain manner which defines the gender roles we put them in and to be quiet and to not shout or laugh loudly. We create a stigma of things which defines: Nice. And anything out of that is obscure. We need to teach them to be brave and opinionative and true. Rather than this. Because this false nature of parenting makes them quite which lead people to use them without their consent. And consent matters. Because this justification of being nice makes them prey of violence that happens against them and they don't voice out because they want to be likeable. And Men are always aggressive because that's how men are, this justification makes them get away with everything and sometimes cause them trouble which they never saw coming. Such things happen because of certain gender roles we put young girls and boys through. From being likeable and to being aggressive as a natural act of two genders in where we set these boundaries which later become problems and as Adichie suggest we need understand the problem and teach young kids to be true and brave.

Adichie suggests about giving her a sense of identity. She suggests to teach her about the Igbo culture and all the rights and wrongs about it. So that she will have an identity of roots and she can decide for herself and will go away from the norms which are created to belittle other cultures. Because we come from postcolonial era, we tend to white wash things around us unconsciously. It is important to make our ourselves and upcoming generation to understand the history of our country, our culture and diaspora. It is important part of 
parenting where they will make sure that they are not insecure because of their ethnicity. Which will also give them the sense of self identity when we will teach them every good and bad thing about the history and culture.

Adichie suggests in the later parts about sex and education. She emphasises on talking about it with your kids as soon as possible. Because it opens up new doors of information and help them avoid miscommunication that happens in later stages of life. Female body is looked upon and shown something which is sacred and hidden. It's also something which women itself sometimes sees it in negative light. Which is endured because of lack of communication about it. Women are taught to look upon sexuality with shame. She says:

"The shame we attach to female sexuality is about control. Many cultures and religions control women's bodies in one way or another. If the justification for controlling women's bodies were about women themselves, then it would be understandable. If, for example, the reason was 'women should not wear short skirts because they can get cancer if they do'. Instead the reason is not about women, but about men. Women must be 'covered up' to protect men. I find this deeply dehumanizing because it reduces women to mere props used to manage the appetites of men."

We never teach these things to young boys, which is also the cause of problem. We try to present sex education in the hidden sense that it becomes hazy and confused for young kids to understand. Which is as dangerous as not knowing anything about it. Women should know about their bodies and sexuality, so does men. We need to create an atmosphere where they can talk about it and question about things which confuse them. But what generally happens is this confusion become so dangerous for them that sex become something mysterious which they need to find on their own and in such a vile manner. Parenting where anyone can openly discuss about things which bothers them, is the kind of parenting which 
can be useful for the upbringing of generation. Because culture changes, things are never constant so why not being in twenty first century, we look forward to better our society by unlearning things and try to accept the change which has potential to change society for better.

Teach girls to be economically stable and make sure to never turn oppression into saintliness. She talks about the female misogyny and that it exists and how we need to make sure to give girls the upbringing where they try to dislocate themselves from it. She says: "And there are many women in the world who do not like other women. Female misogyny exists, and to evade acknowledging it is to create unnecessary opportunities for anti-feminists to try to discredit feminism. I mean the sort of anti-feminists who will gleefully raise examples of women saying 'I am not a feminist' as though a person born with a vagina making this statement somehow automatically discredits feminism. That a woman claims not to be feminist does not diminish the necessity of feminism. If anything, it makes us see the extent of the problem, the successful reach of patriarchy. It shows us, too, that not all women are feminists and not all men are misogynists."

Her suggestion clearly points out on the patriarchy which is deeply embedded in everyone. We need to understand the "we" in womanhood does not exist. Yes, women are part of patriarchy but as well as men, but men never blame other men for their wrong doing but women also blame women. As Cixous says:

"Men have committed the greatest crime against women. Insidiously, violently, they have led them to hate women, to be their own enemies, to mobilize their immense strength against themselves, to be executants of their virile needs. They have made for women an anti-narcissism! A narcissism which loves itself only to 
be loved for what women haven't got! They have constructed the infamous logic of antilove."

The course of romance which seems problematic today. A relationship between men and women today is going in direction which gives wrong message. Again, the notion allowing comes back and the blind acceptance with it. Adichie suggests to stay away from the relations where there is not equality and by equality means away from all sorts of small gestures. Yes, there can be change and the acceptance of change is something which can be worked on. But never leave your premise in order to fit in some relationships. Because we see young girls today trying to accommodate themselves with things which their partner loves. That's where problem lies, because they can't pretend for too long. Women in love can lose themselves fully in their love affairs without fully being truly understood. We need to accept changes we need to create changes as well but should be clear with our own premises as well.

Lastly teach her to accept the difference and make difference as long as it is not harming anyone. Difference is the reality of the world, and we teach them about difference we will make them survive in the diverse world. Where they will able to adapt situations which are different, where people are different yet they coexist equally.

Adichie being a contemporary writer who speaks about Nigeria with the reference of postcolonial era. Her perspective on feminism is needed today to have a better understanding of it. And her works give new perspective on things which are said progressive are really not. By choosing specifically Dear Ijeawele or a Feminist Manifesto in Fifteen Suggestions for this paper is the way it was written in such a simple and detailed manner. The suggestions given by her are very basic and yet something we overlook. She suggests a kind of parenting which is very important today and can be accommodated with gender neutral parenting. I believe it can be used as a part of gender-neutral parenting. And by mentioning her other famous works my motive was to show the contemporary situations with same rigid binaries 
which are embedded in or society and her views which she put forward in her works are refreshing and yet very relevant. Which also gives us the better understanding of Nigerian Literature. 


\section{References}

Adichie, Amanda N. We Should All Be Feminists.

Adichie, Chimamanda Ngozi. Dear Ijeawele, Or, A Feminist Manifesto In Fiftee Suggestions.

Cixous, Hélène. The Laugh Of Medusa.

Gould, Lois. The Story Of X. 2018.

Showalter, Elaine. Feminist Criticism In The Wilderness. 